\title{
Factors influencing health-related quality of life after gastrectomy for cancer
}

\author{
Hylke J. F. Brenkman ${ }^{1}$ Juul J. W. Tegels ${ }^{2} \cdot$ Jelle P. Ruurda $^{1} \cdot$ Misha D. P. Luyer $^{3} \cdot$ Ewout A. Kouwenhoven $^{4} \cdot$ \\ Werner A. Draaisma ${ }^{5}$ Donald L. van der Peet ${ }^{6} \cdot$ Bas P. L. Wijnhoven $^{7} \cdot$ Jan H. M. B. Stoot $^{2}$

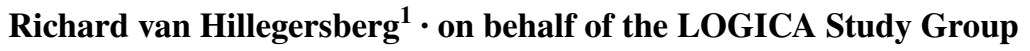

Received: 19 June 2017 / Accepted: 28 September 2017 / Published online: 24 October 2017

(C) The Author(s) 2017. This article is an open access publication

\begin{abstract}
Aim Insight in health-related quality of life (HRQoL) may improve clinical decision making and inform patients about the long-term effects of gastrectomy. This study aimed to evaluate and identify factors associated with HRQoL after gastrectomy.

Methods This cross-sectional study used prospective databases from seven Dutch centers (2001-2015) including patients who underwent gastrectomy for cancer. Between July 2015 and November 2016, European Organization for Research and Treatment of Cancer HRQoL questionnaires
\end{abstract}

Electronic supplementary material The online version of this article (doi:10.1007/s10120-017-0771-0) contains supplementary material, which is available to authorized users.

Richard van Hillegersberg

R.vanHillegersberg@umcutrecht.nl

Hylke J. F. Brenkman

H.J.F.Brenkman@umcutrecht.nl

1 Department of Surgery, Division Cancer Center, University Medical Center Utrecht, Heidelberglaan 100, 3508 GA Utrecht, The Netherlands

2 Department of Surgery, Zuyderland Medical Center, Sittard, The Netherlands

3 Department of Surgery, Catharina Hospital, Eindhoven, The Netherlands

4 Department of Surgery, Ziekenhuisgroep Twente, Almelo, The Netherlands

5 Department of Surgery, Meander Medical Center, Amersfoort, The Netherlands

6 Department of Surgery, VU Medical Center, Amsterdam, The Netherlands

7 Department of Surgery, Erasmus Medical Center, Rotterdam, The Netherlands
QLQ-C30 and QLQ-STO22 were sent to all surviving patients without recurrence. The QLQ-C30 scores were compared to a Dutch reference population using a one-sample $t$ test. Spearman's rank test was used to correlate time after surgery to HRQoL, and multivariable linear regression was performed to identify factors associated with HRQoL. Results A total of 222 of 274 (81.0\%) patients completed the questionnaires. Median follow-up was 29 months (range, $3-171$ ) and $86.9 \%$ of patients had a follow-up $>1$ year. The majority of patients had undergone neoadjuvant treatment (64.4\%) and total gastrectomy (52.7\%). Minimally invasive gastrectomy (MIG) was performed in 50\% of the patients. Compared to the general population, gastrectomy patients scored significantly worse on most functional and symptom scales $(p<0.001)$ and slightly worse on global HRQoL (78 vs. $74, p=0.012$ ). Time elapsed since surgery did not correlate with global HRQoL (Spearman's $\rho=0.06, p=0.384$ ). Distal gastrectomy, neoadjuvant treatment, and MIG were associated with better HRQoL $(p<0.050)$.

Conclusion After gastrectomy, patients encounter functional impairments and symptoms, but experience only a slightly impaired global HRQoL. Distal gastrectomy, the ability to receive neoadjuvant treatment, and MIG may be associated with HRQoL benefits.

Keywords Gastric cancer - Gastrectomy - Quality of life

\section{Introduction}

Gastric cancer is the fifth most common type of cancer worldwide [1], and surgical resection is the cornerstone of treatment with curative intent. Because survival after gastrectomy for cancer has improved since the introduction of a more extensive lymphadenectomy and perioperative 
chemotherapy $[2,3]$, the quality of life following treatment has become increasingly important. Various complaints that are associated with the treatment, such as a loss of appetite, early satiety, reflux, dysphagia, nausea, and change of stools, may have a profound impact on patient health-related quality of life (HRQoL) [4].

HRQoL is multidimensional, comprising physical, medical, psychological, and social parameters secondary to a disease and its treatment, and is considered as one of the most important outcome measurements in cancer treatment nowadays. Evaluating HRQoL helps health professionals to focus on certain aspects to improve current treatment strategies. Moreover, understanding HRQoL in patients after surgery for gastric cancer is useful for informing patients about the (long-term) risks and benefits of an intervention.

High-quality studies evaluating HRQoL after gastrectomy for cancer in Western countries are scarce. In addition, it is unknown if the HRQoL of patients after gastrectomy differs from HRQoL in the general population. The aim of this multicenter cross-sectional study was therefore to evaluate HRQoL in patients who underwent gastrectomy for cancer in relationship to the general population and to identify factors influencing HRQoL.

\section{Methods}

\section{Study design}

This cross-sectional multicenter cohort study included data from seven referral centers for gastric cancer surgery in the Netherlands. All data were extracted from prospectively collected institutional databases. Institutional Review Board approval was obtained, and informed consent requirement was waived for this study.

\section{Patient population}

This study included patients who underwent gastrectomy for gastric adenocarcinoma between 2001 and 2015. Only patients who were alive and free of disease were approached for participation. According to national guidelines, patients received either perioperative treatment and gastrectomy or gastrectomy alone [5]. Staging was performed in accordance with the 7th American Joint Committee on Cancer TNM staging system $[6,7]$. Information on patient, treatment, and histopathological characteristics were collected from the prospective institutional databases. Follow-up was updated retrospectively.

\section{Quality of life}

Cross-sectional HRQoL was measured by means of the European Organisation for Research and Treatment of Cancer (EORTC) questionnaires. The EORTC-QLQ-C30 was developed to assess the HRQoL of patients with cancer in general [8]; the EORTC-QLQ-STO22 was developed to assess the HRQoL of patients with gastric cancer specifically [4]. The EORTC-QLQ-C30 and EORTC-QLQ-STO22 consist of 30 and 22 questions, respectively, scored on a 4- or 7-point Likert scale, which are translated to a global QoL scale, functional scales (physical, role, emotional, cognitive, social, and body image), and symptom scales (fatigue, nausea and vomiting, pain, dyspnea, insomnia, appetite loss, constipation, diarrhea, financial difficulties, dysphagia, reflux, eating restrictions, anxiety, dry mouth, taste, and hair loss). Higher scores in global HRQoL and functional scales indicate better HRQoL, whereas higher scores in the symptom scales indicate more severe symptoms. Patients were contacted to complete the questionnaires by mail, and received one reminder by telephone in the case of no response.

\section{Statistical analyses}

HRQoL data obtained by the questionnaires were scored according to the manual [9]. The patients' HRQoL scores of the EORTC-QLQ-C30 were compared to a general Dutch reference population consisting of 1731 individuals by performing one-sample $t$ tests [10]. Subgroup analyses were performed on age and gender, and of patients who had a follow-up $\geq 12$ months. Based on previous studies, a difference in HRQoL $>10$ points was considered clinically relevant [11]. A Spearman's rank correlation coefficient $(\rho)$ was calculated to measure the dependence of different HRQoL scores to time since surgery. A positive or negative correlation coefficient was considered very strong if $\rho>0.8$, strong if $\rho=0.6-0.8$, moderate if $\rho=0.4-0.6$, weak if $\rho=0.2-0.4$, and very weak if $\rho<0.2$. Finally, multivariable linear regression analysis with stepwise backward elimination was performed to evaluate the association between HRQoL scales and patient, surgical, and histopathological variables. These variables were chosen based on their possible association with HRQoL as demonstrated by previous studies [12-16]. Major complications were defined as complications requiring a re-intervention or intensive care admission. A $p$ value $<0.05$ was considered statistically significant. All statistical analyses were performed using IBM SPSS version 21 . 


\section{Results}

\section{Patients}

A total of 683 patients who underwent gastrectomy for gastric adenocarcinoma were identified from the combined database. Some 409 patients were excluded because of death or recurrent disease. The remaining 274 patients were invited to participate in the study and were sent HRQoL questionnaires. The questionnaires were completed by 222 of $274(81.0 \%)$ patients (Supplementary file 1).

\section{Baseline}

There were no differences in patient and tumor characteristics, nor in postoperative outcomes, of respondents $(n=222)$ and non-respondents $(n=52)$. The median follow-up at completing the questionnaires was 29 months (range, 3-171); $193(86.9 \%)$ of the respondents had a follow-up $>1$ year, whereas $40(18.0 \%)$ had a follow-up $>5$ years (Fig. 1). Patient, surgical, and histopathological characteristics of the patients are shown in Table 1. Some $143(64.4 \%)$ patients had undergone neoadjuvant treatment, 117 patients $(52.7 \%)$ a total gastrectomy, and 111 patients (50.0\%) a minimally invasive gastrectomy (MIG). Of the patients receiving perioperative treatment, most received perioperative chemotherapy according to a regimen similar to epirubicin, cisplatin, and capecitabin [3]. Radiotherapy was not routinely performed, except for some patients who received adjuvant chemoradiation as part of the CRITICS trial [17]. The majority of patients $(n=119,53.6 \%)$ had an advanced tumor stage $(\geq \mathrm{II})$. Major postoperative complications were seen in $42(18.9 \%)$ patients. Median hospital stay was 9 days (range, 3-124), and 24 (10.8\%) patients were readmitted within 30 days after discharge.

\section{HRQoL versus reference population}

The mean HRQoL score and standard deviation of the study population and the reference population are shown in Table 2 [10]. Patients who underwent gastrectomy for cancer had statistically significantly lower scores than the reference population for all functional scales $(p<0.001)$ and most general symptom scales $(p<0.002)$, expect for pain symptoms ( $p=0.067$ ) (Table 2$)$. This difference was clinically relevant for most scales (physical, role, cognitive, and social functioning; fatigue, nausea, and vomiting, dyspnea, appetite loss, diarrhea, and financial difficulties). On global HRQoL, patients scored significantly worse compared to the reference population, although this difference was clinically irrelevant (weight mean difference $=4, p=0.002$ ). The distribution of global HRQoL scores is shown in Fig. 2: 78\% of patients scored a global HRQoL $>60$, compared to $83 \%$ in the reference population $(p=0.027)$.

In a subgroup analysis of men or women compared to a reference population of comparable age (60-69 years), similar results (as demonstrated in Table 2) were found (Supplementary files 2 and 3 ). In addition, subgroup analyses of patients with a follow-up $\geq 12$ months also did not influence the results (Supplementary file 4).

\section{HRQoL and time elapsed since surgery}

Spearman rank correlation coefficients between HRQoL and time after surgery were calculated, demonstrating weak correlations ranging from -0.13 to +0.13 (Table 3 ). In patients with follow-up $<1$ year, a larger variation of correlations was present, ranging from -0.46 to +0.29 . Moreover, there was no difference in HRQoL between the years of surgery $(p=0.523)$.
Fig. 1 Timing of quality of life (QoL) questionnaire (months after surgery)

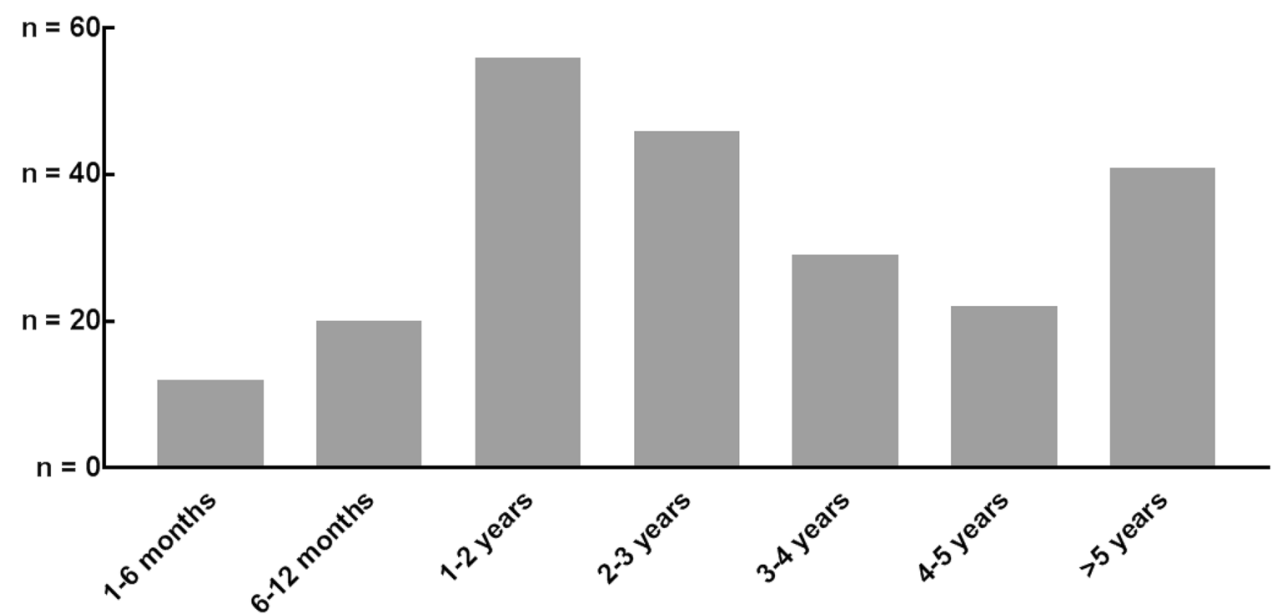


Table 1 Baseline characteristics of 222 patients who underwent gastrectomy for cancer

\begin{tabular}{|c|c|}
\hline Factor & $n=222(\%)$ \\
\hline Age (years) [mean $( \pm S D)]$ & $67.7( \pm 10.6)$ \\
\hline BMI $\left(\mathrm{kg} / \mathrm{m}^{2}\right)[$ mean $( \pm \mathrm{SD})]$ & $25.5( \pm 4.4)$ \\
\hline \multicolumn{2}{|l|}{ Gender } \\
\hline Male & $141(63.5)$ \\
\hline Female & $81(36.5)$ \\
\hline \multicolumn{2}{|l|}{ Malignancy history } \\
\hline No & $157(86.3)$ \\
\hline Yes & $25(14.7)$ \\
\hline Unknown & 40 \\
\hline Comorbidity & $169(76.1)$ \\
\hline Cardiovascular & $110(49.5)$ \\
\hline Pulmonary & $37(16.7)$ \\
\hline Diabetes mellitus & $37(16.7)$ \\
\hline \multicolumn{2}{|l|}{ ASA } \\
\hline I & $33(14.9)$ \\
\hline II & $141(63.5)$ \\
\hline III & $46(20.7)$ \\
\hline IV & $2(0.9)$ \\
\hline Neoadjuvant treatment & $143(64.4)$ \\
\hline Adjuvant treatment & $67(30.2)$ \\
\hline \multicolumn{2}{|l|}{ Year of surgery } \\
\hline 2001-2004 & $3(11.4)$ \\
\hline 2005-2009 & $10(4.5)$ \\
\hline 2010-2012 & $66(29.7)$ \\
\hline 2013-2015 & $143(64.4)$ \\
\hline \multicolumn{2}{|l|}{ Surgical type } \\
\hline Distal gastrectomy & $105(47.3)$ \\
\hline Total gastrectomy & $117(52.7)$ \\
\hline \multicolumn{2}{|l|}{ Surgical approach } \\
\hline Open & $111(50.0)$ \\
\hline Laparoscopic & $111(50.0)$ \\
\hline Complications & $89(40.1)$ \\
\hline Major & $42(18.9)$ \\
\hline Anastomotic leakage & $16(7.2)$ \\
\hline Pulmonary & $24(10.8)$ \\
\hline Hospital stay (median, range) (days) & $9(3-124)$ \\
\hline \multicolumn{2}{|l|}{ Radicality } \\
\hline R0 & $214(96.4)$ \\
\hline $\mathrm{R}+$ & $5(2.3)$ \\
\hline Missing & $3(1.4)$ \\
\hline \multicolumn{2}{|l|}{ pTNM stage } \\
\hline 0 & $15(6.8)$ \\
\hline I & $88(39.6)$ \\
\hline II & $78(35.1)$ \\
\hline III & $40(18.0)$ \\
\hline IV & $1(0.5)$ \\
\hline
\end{tabular}

Table 2 Mean (standard deviations) health-related quality of life (HRQoL) scores of 222 patients who underwent gastrectomy for cancer compared to the general Dutch population

\begin{tabular}{|c|c|c|c|c|}
\hline & Total $n=222$ & $\begin{array}{l}\text { Reference } \\
\text { population } \\
n=1731\end{array}$ & WMD & $p$ value \\
\hline \multicolumn{5}{|c|}{ Quality of life questionnaire (QLQ)-C30 } \\
\hline $\begin{array}{l}\text { Global quality of } \\
\text { life }^{\mathrm{a}}\end{array}$ & $74[21]$ & $78[17]$ & -4 & 0.002 \\
\hline \multicolumn{5}{|l|}{ Functional scales ${ }^{\mathrm{a}}$} \\
\hline Physical & $79[20]$ & $90[15]$ & -11 & $<0.001$ \\
\hline Role & 73 [29] & $89[21]$ & -16 & $<0.001$ \\
\hline Emotional & $81[24]$ & $89[16]$ & -8 & $<0.001$ \\
\hline Cognitive & $81[22]$ & $92[15]$ & -11 & $<0.001$ \\
\hline Social & $81[26]$ & $94[16]$ & -13 & $<0.001$ \\
\hline \multicolumn{5}{|c|}{ General symptom scales ${ }^{\mathrm{b}}$} \\
\hline Fatigue & $33[27]$ & $17[20]$ & +16 & $<0.001$ \\
\hline $\begin{array}{l}\text { Nausea and } \\
\text { vomiting }\end{array}$ & $14[22]$ & $2.7[10]$ & +11 & $<0.001$ \\
\hline Pain & 18 [26] & $15[22]$ & +3 & 0.067 \\
\hline Dyspnoea & $18[25]$ & $7.1[17]$ & +11 & $<0.001$ \\
\hline Insomnia & 20 [29] & $14[23]$ & +6 & 0.002 \\
\hline Appetite loss & $21[32]$ & $3.3[12]$ & +18 & $<0.001$ \\
\hline Constipation & $10[22]$ & $4.8[14]$ & +5 & 0.001 \\
\hline Diarrhea & $18[26]$ & $3.9[14]$ & +14 & $<0.001$ \\
\hline $\begin{array}{l}\text { Financial dif- } \\
\text { ficulties }\end{array}$ & 16 [29] & $3.1[13]$ & +13 & $<0.001$ \\
\hline \multicolumn{5}{|l|}{ QLQ-STO22 } \\
\hline \multicolumn{5}{|l|}{ Functional scales ${ }^{\mathrm{a}}$} \\
\hline Body image & $82[28]$ & NA & & NA \\
\hline \multicolumn{5}{|c|}{ General symptom scales ${ }^{\mathrm{b}}$} \\
\hline Dysphagia & 16 [21] & NA & & NA \\
\hline Pain & 20 [22] & NA & & NA \\
\hline Reflux & 22 [25] & NA & & NA \\
\hline $\begin{array}{l}\text { Eating restric- } \\
\text { tions }\end{array}$ & 25 [25] & NA & & NA \\
\hline Anxiety & 30 [27] & NA & & NA \\
\hline Dry mouth & 21 [30] & NA & & NA \\
\hline Taste & 17 [29] & NA & & NA \\
\hline Hair loss & 18 [32] & NA & & NA \\
\hline
\end{tabular}

Scores are presented as mean $[ \pm \mathrm{SD}]$

${ }^{\text {a }}$ Score range 0-100: higher scores represent a better quality of life or level of functioning

${ }^{\mathrm{b}}$ Score range 0-100: higher scores represent more severe symptoms Bold values indicate significant variables $(p<0.05)$

\section{Predictive factors for HRQoL}

Global HRQoL was significantly higher in patients who underwent distal gastrectomy [+6.5, 95\% CI $(0.8 ; 12)$, $p=0.026]$ and neoadjuvant treatment $[+8.2,95 \% \mathrm{CI}$ $(1.8 ; 15), p=0.012]$. Moreover, both distal gastrectomy and neoadjuvant treatment were associated with better 
Fig. 2 Distribution of global HRQOL-scores (EORTCQLQ-C30) of 222 patients who underwent gastrectomy for cancer compared to the general Dutch population

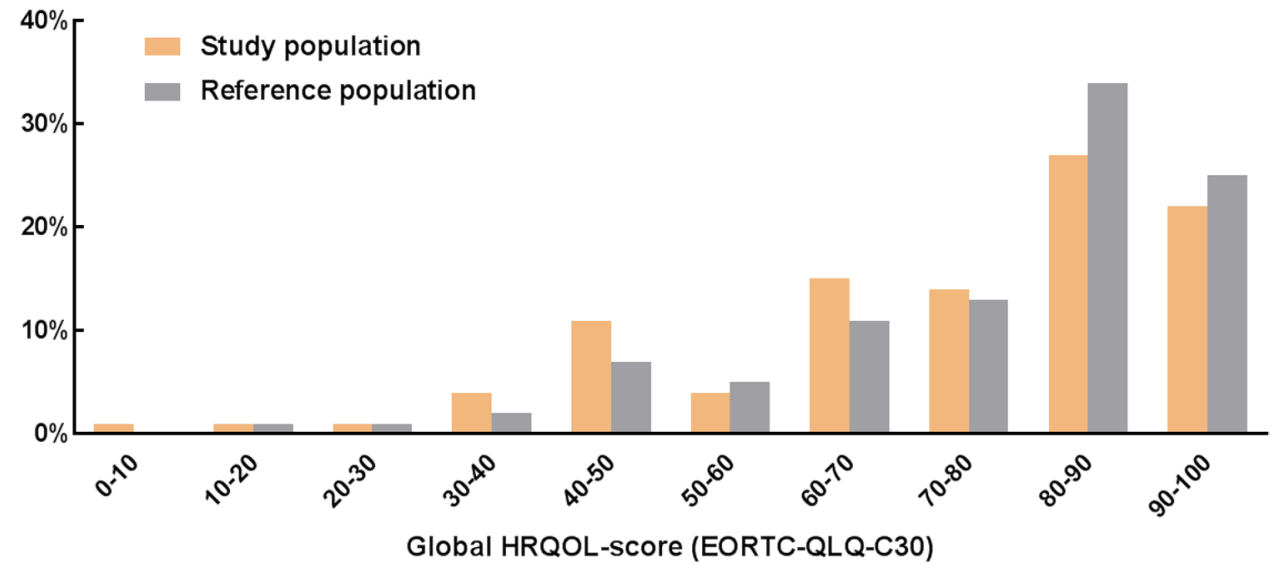

Table 3 Spearman's rank correlation coefficients between quality of life and length of follow-up (FU) since surgery

\begin{tabular}{|c|c|c|c|}
\hline & \multicolumn{3}{|c|}{ Spearman's rank coefficient $(\rho)$} \\
\hline & $\begin{array}{l}\text { Total cohort } \\
(n=222)\end{array}$ & $\begin{array}{l}\text { Follow-up } \\
<1 \text { year } \\
(n=29)\end{array}$ & $\begin{array}{l}\text { Follow-up } \\
>1 \text { year } \\
(n=193)\end{array}$ \\
\hline \multicolumn{4}{|c|}{ Quality of life questionnaire (QLQ)-C30 } \\
\hline Global quality of life ${ }^{\mathrm{a}}$ & +0.06 & -0.01 & +0.11 \\
\hline \multicolumn{4}{|l|}{ Functional scales $^{\mathrm{a}}$} \\
\hline Physical & -0.08 & -0.11 & -0.03 \\
\hline Role & -0.02 & -0.17 & +0.06 \\
\hline Emotional & +0.07 & -0.11 & +0.14 \\
\hline Cognitive & +0.08 & +0.10 & +0.20 \\
\hline Social & +0.03 & -0.03 & +0.07 \\
\hline \multicolumn{4}{|l|}{ General symptom scales $^{\mathrm{b}}$} \\
\hline Fatigue & +0.08 & +0.29 & -0.01 \\
\hline Nausea and vomiting & +0.07 & -0.14 & +0.06 \\
\hline Pain & +0.06 & +0.03 & -0.01 \\
\hline Dyspnea & +0.03 & +0.17 & -0.03 \\
\hline Insomnia & +0.04 & -0.11 & -0.05 \\
\hline Appetite loss & -0.02 & -0.25 & -0.05 \\
\hline Constipation & -0.07 & -0.17 & -0.08 \\
\hline Diarrhea & +0.07 & -0.06 & +0.09 \\
\hline Financial difficulties & -0.02 & -0.14 & -0.06 \\
\hline \multicolumn{4}{|l|}{ QLQ-STO22 } \\
\hline \multicolumn{4}{|l|}{ Functional scales ${ }^{\mathrm{a}}$} \\
\hline Body image & +0.03 & +0.25 & +0.02 \\
\hline \multicolumn{4}{|l|}{ General symptom scales ${ }^{b}$} \\
\hline Dysphagia & -0.03 & -0.32 & -0.03 \\
\hline Pain & -0.02 & -0.16 & -0.09 \\
\hline Reflux & +0.13 & +0.01 & +0.13 \\
\hline Eating restrictions & -0.11 & -0.11 & -0.07 \\
\hline Anxiety & -0.11 & -0.03 & -0.13 \\
\hline Dry mouth & +0.02 & -0.03 & +0.03 \\
\hline Taste & -0.13 & +0.05 & -0.13 \\
\hline Hair loss & -0.05 & -0.46 & -0.03 \\
\hline
\end{tabular}

$F U$ follow-up

Bold values indicate significant variables $(p<0.05)$
HRQoL scores in other symptom and functioning scales (Table 4). Minimally invasive surgery resulted in significantly better HRQoL scores on physical functioning $[+7.5$ $(2.4 ; 12), p=0.004]$, fatigue $[-7.0(-14 ;-0.05), p=0.048]$, pain $[-9.1(-16 ;-2.6), p=0.007]$, and dry mouth $[-9.5$ $(-17 ;-1.8), p=0.015]$. Furthermore, female gender and a high ASA score were predictive factors for impaired HRQoL in some scales.

\section{Discussion}

This cross-sectional multicenter study demonstrates that patients who underwent gastrectomy experienced functional complaints and symptoms, whereas global HRQoL was only slightly lower compared to the Dutch reference population. Most importantly, distal gastrectomy and the ability to receive neoadjuvant treatment were associated with higher global HRQoL, whereas minimally invasive surgery was associated with better functional and symptom scores.

The results of this study are relevant, as they may represent the average population undergoing gastrectomy for cancer in the West. Unfortunately, to date, most studies on HRQoL after gastrectomy lacked data on patient characteristics [12], were performed in the Asian population [13-15], or selected patients by age [14], minimally invasive procedures [13, 14], comorbidities [13, 14], tumor stage [15], or perioperative chemotherapy [16]. The present study is the first study to include all disease-free patients who underwent gastrectomy for cancer and to compare the results to a general Western reference population.

This study demonstrated that the absolute difference in global HRQoL compared to the general population is clinically irrelevant. These findings correspond with previous studies on HRQoL after other types of cancer surgery, such as esophagectomy [18] and breast cancer surgery [19], and demonstrate that patients can achieve a high life satisfaction after surviving cancer, regardless of the presence of 


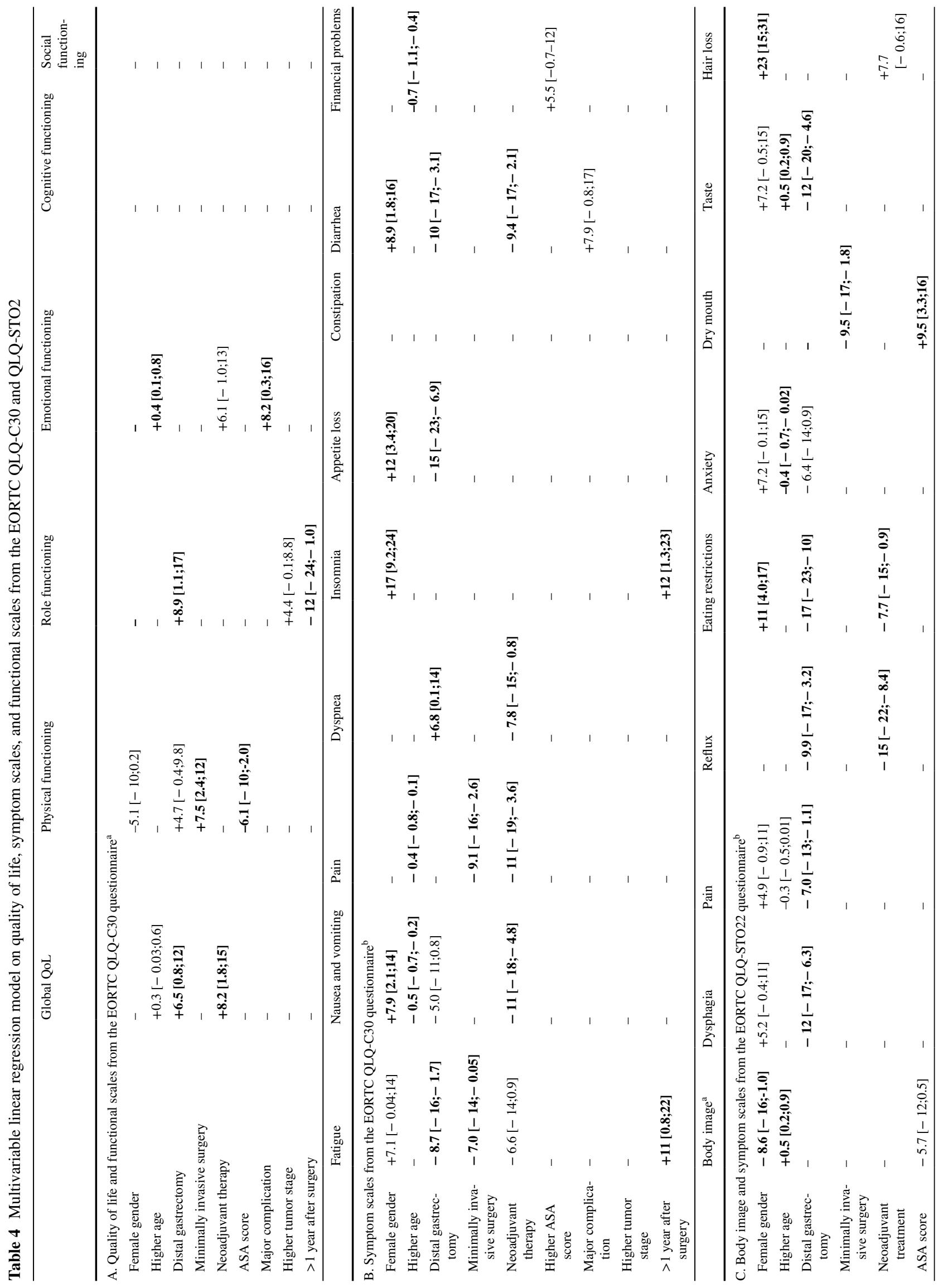




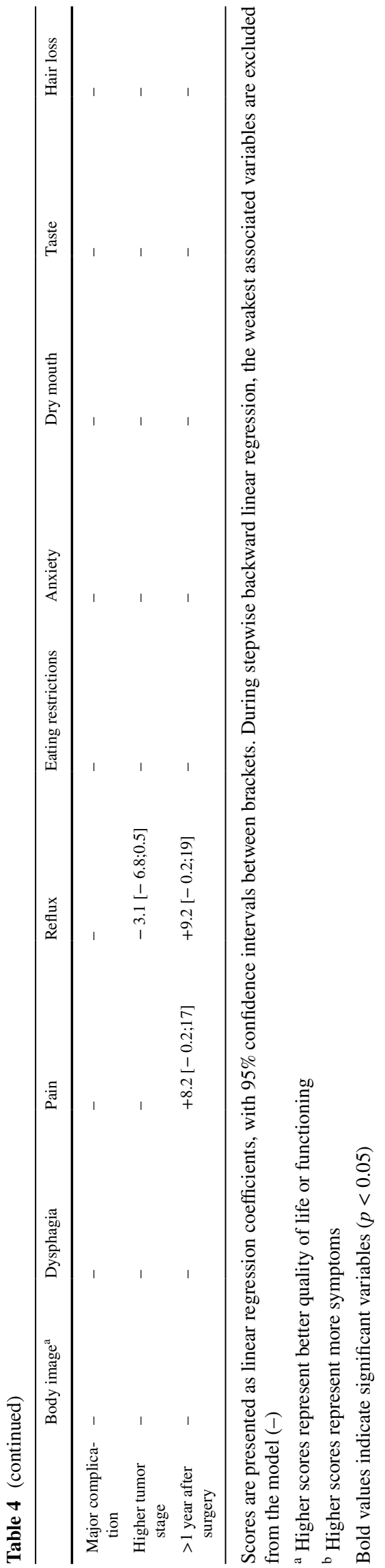

symptoms or functional impairment. This adjustment might be explained by a phenomenon called reconceptualization, which is well known in HRQoL assessments [20]. Reconceptualization implies that certain circumstances, such as surviving cancer, can alter the internal reference points of an individual's well-being that are critical for an evaluation of HRQoL. As a result, objective impairments in different areas of life can be measured, but the overall HRQoL is based on other factors and can therefore be compared to data before the circumstance or from the general population [14].

HRQoL benefits of minimally invasive gastrectomy over open gastrectomy were also demonstrated by an Asian randomized controlled trial [15]. Comparable benefits were found on physical functioning and symptoms. However, benefits in global HRQoL could not be confirmed by the present study. This difference could be explained because the present study evaluated a population with longer follow-up, whereas one might expect global HRQoL benefits of minimally invasive surgery mainly in the short term. Although minimally invasive gastrectomy may have additional advantages over open gastrectomy [21-25], results from more randomized controlled trials are awaited [26-28].

Other factors possibly influencing HRQoL identified in this study were the extent of gastrectomy, neoadjuvant treatment, gender, and time since surgery. During distal gastrectomy, a functional part of the stomach is preserved and a less extensive lymphadenectomy is required [29], contributing to a higher HRQoL compared to total gastrectomy on several domains $[13,30]$. An interesting finding is the higher HRQoL in patients who were able to receive neoadjuvant treatment, compared to patients who did not receive neoadjuvant treatment. Although chemotherapy has been shown to increase HRQoL in the palliative setting [31], the only evidence available in the curative setting demonstrates that physical fitness of patients decreases during neoadjuvant treatment [32]. The lower HRQoL after gastrectomy found in women is consistent with previous studies and the general reference population [10, 18]. Elapsed time since surgery did not correlate with HRQoL, which may be a result of the long-term follow-up of patients in this study. Previous studies have demonstrated that time since surgery is mainly associated with HRQoL in the early recovery period [16], whereas QoL remains relatively stable after the first year following surgery [33].

There are some limitations of this study that need to be addressed. First, although subgroup analyses of males and females of comparable age were performed, we cannot exclude confounding caused by differences between the study population and general population in baseline. Second, because patients with undiagnosed recurrent disease might have been included, this factor could have decreased the HRQoL measured in the study population [16]. Third, despite correcting for confounding factors, selection bias 
cannot be fully excluded. For instance, selection bias might explain the higher HRQoL in patients who received neoadjuvant treatment. Another form of selection bias might be caused by the inclusion of mainly long-term survivors, which may have led to an overestimation of the quality of life of patients following gastrectomy in this study. Last, the cross-sectional design of this study did not allow the analysis of repeated measurements of HRQoL over time.

In conclusion, although surviving patients experience significant symptoms and functional problems after gastrectomy, global HRQoL is more or less comparable to the general population. Distal gastrectomy, the ability to receive neoadjuvant treatment, and minimally invasive surgery could be associated with HRQoL benefits and may therefore be preferred. The results of this study may help healthcare professionals during clinical decision making and the preoperative process of informed consent.

Acknowledgements The authors thank Peter van Rossum for his assistance in the statistical analyses, and Nicole van der Wielen, Judith Schots, Rob Tolboom, and Ilse Masselink for their help in obtaining the HRQoL data.

\section{Compliance with ethical standards}

Conflict of interest The authors have nothing to disclose. All authors are participants of the LOGICA-trial consortium, a trial comparing open versus laparoscopic gastrectomy funded by a ZonMw Health Care Efficiency Grant (ID: 237002502).

Human rights statement All procedures followed were in accordance with the ethical standards of the responsible committee on human experimentation (institutional and national) and with the Helsinki Declaration of 1964 and later versions.

Informed consent Ethical review board approval was obtained and informed consent was waived.

Open Access This article is distributed under the terms of the Creative Commons Attribution 4.0 International License (http://creativecommons.org/licenses/by/4.0/), which permits unrestricted use, distribution, and reproduction in any medium, provided you give appropriate credit to the original author(s) and the source, provide a link to the Creative Commons license, and indicate if changes were made.

\section{References}

1. Ferlay J, Soerjomataram I, Dikshit R, et al. Cancer incidence and mortality worldwide: sources, methods and major patterns in GLOBOCAN 2012. Int J Cancer. 2015;136:E359-86.

2. Hartgrink HH, van de Velde CJ, Putter H, et al. Extended lymph node dissection for gastric cancer: who may benefit? Final results of the randomized Dutch gastric cancer group trial. J Clin Oncol. 2004;22:2069-77.

3. Cunningham D, Allum WH, Stenning SP, et al. Perioperative chemotherapy versus surgery alone for resectable gastroesophageal cancer. N Engl J Med. 2006;355:11-20.
4. Blazeby JM, Conroy T, Bottomley A, et al. Clinical and psychometric validation of a questionnaire module, the EORTC QLQSTO 22, to assess quality of life in patients with gastric cancer. Eur J Cancer. 2004;40:2260-8.

5. Vereniging Integrale Kankercentra. Diagnostiek, behandeling en follow-up van het maagcarcinoom 2009. Available at: http://www. oncoline.nl/uploaded/docs/Maagcarcinoom/Richtlijn\%20maagcarcinoom.pdf

6. Washington K. 7th edition of the AJCC cancer staging manual: stomach. Ann Surg Oncol. 2010;17:3077-9.

7. Edge S, Byrd D, Compton C, et al. AJCC cancer staging manual. New York: Springer; 2010.

8. Aaronson NK, Ahmedzai S, Bergman B, et al. The European Organization for Research and Treatment of Cancer QLQ-C30: a quality-of-life instrument for use in international clinical trials in oncology. J Natl Cancer Inst. 1993;85:365-76.

9. Fayers P, Aaronson N, Bjordal K, et al. The EORTC QLQ-C30 Scoring Manual. Brussels: European Organisation for Research and Treatment of Cancer; 2001.

10. van de Poll-Franse LV, Mols F, Gundy CM, et al. Normative data for the EORTC QLQ-C30 and EORTC-sexuality items in the general Dutch population. Eur J Cancer. 2011;47:667-75.

11. Osoba D, Rodrigues G, Myles J, et al. Interpreting the significance of changes in health-related quality-of-life scores. J Clin Oncol. 1998;16:139-44.

12. Karanicolas PJ, Graham D, Gonen M, et al. Quality of life after gastrectomy for adenocarcinoma: a prospective cohort study. Ann Surg. 2013;257:1039-46.

13. Lee SS, Chung HY, Kwon OK, et al. Long-term quality of life after distal subtotal and total gastrectomy: symptom- and behavior-oriented consequences. Ann Surg. 2016;263:738-44.

14. Lee SS, Chung HY, Kwon O, et al. Long-term shifting patterns in quality of life after distal subtotal gastrectomy: preoperative- and healthy-based interpretations. Ann Surg. 2015;261:1131-7.

15. Kim YW, Baik YH, Yun YH, et al. Improved quality of life outcomes after laparoscopy-assisted distal gastrectomy for early gastric cancer: results of a prospective randomized clinical trial. Ann Surg. 2008;248:721-7.

16. Avery K, Hughes R, McNair A, et al. Health-related quality of life and survival in the 2 years after surgery for gastric cancer. Eur $\mathrm{J}$ Surg Oncol. 2010;36:148-54.

17. Dikken JL, van Sandick JW, Maurits Swellengrebel HA, et al. Neo-adjuvant chemotherapy followed by surgery and chemotherapy or by surgery and chemoradiotherapy for patients with resectable gastric cancer (CRITICS). BMC Cancer. 2011;11:329.

18. Akkerman RD, Haverkamp L, van Rossum PS, et al. Long-term quality of life after oesophagectomy with gastric conduit interposition for cancer. Eur J Cancer. 2015;51:1538-45.

19. Arndt V, Merx H, Sturmer T, et al. Age-specific detriments to quality of life among breast cancer patients one year after diagnosis. Eur J Cancer. 2004;40:673-80.

20. Blome C, Augustin M. Measuring change in quality of life: bias in prospective and retrospective evaluation. Value Health. 2015; 18:110-5.

21. Kim W, Kim HH, Han SU, et al. Decreased morbidity of laparoscopic distal gastrectomy compared with open distal gastrectomy for stage I gastric cancer: short-term outcomes from a multicenter randomized controlled trial (KLASS-01). Ann Surg. 2015;263:28-35.

22. Hu Y, Huang C, Sun Y, et al. Morbidity and mortality of laparoscopic versus open D2 distal gastrectomy for advanced gastric cancer: a randomized controlled trial. J Clin Oncol. 2016;34:1350-7.

23. Katai H, Mizusawa J, Katayama H, et al. Short-term surgical outcomes from a phase III study of laparoscopy-assisted versus open distal gastrectomy with nodal dissection for clinical stage IA/IB 
gastric cancer: Japan Clinical Oncology Group Study JCOG0912. Gastric Cancer. 2017;20:699-708.

24. Brenkman HJ, Ruurda JP, Verhoeven RH, et al. Safety and feasibility of minimally invasive gastrectomy during the early introduction in the Netherlands: short-term oncological outcomes comparable to open gastrectomy. Gastric Cancer 2017 [Epub ahead of print].

25. Brenkman HJF, Gisbertz SS, Slaman AE, et al. Postoperative Outcomes of Minimally Invasive Gastrectomy Versus Open Gastrectomy During the Early Introduction of Minimally Invasive Gastrectomy in the Netherlands: A Population-based Cohort Study. Ann Surg. 2017;266(5):831-838.

26. Haverkamp L, Brenkman HJ, Seesing MF, et al. Laparoscopic versus open gastrectomy for gastric cancer, a multicenter prospectively randomized controlled trial (LOGICA-trial). BMC Cancer. 2015; 15:556.

27. Straatman J, van der Wielen N, Cuesta MA, et al. Surgical techniques, open versus minimally invasive gastrectomy after chemotherapy (STOMACH trial): study protocol for a randomized controlled trial. Trials. 2015;16:123-9.
28. Hur H, Lee HY, Lee HJ, et al. Efficacy of laparoscopic subtotal gastrectomy with D2 lymphadenectomy for locally advanced gastric cancer: the protocol of the KLASS-02 multicenter randomized controlled clinical trial. BMC Cancer. 2015;15:355.

29. Japanese Gastric Cancer Association. Japanese gastric cancer treatment guidelines 2010 (ver. 3). Gastric Cancer. 2011;14:113-23.

30. Diaz De Liano A, Oteiza Martinez F, Ciga MA, et al. Impact of surgical procedure for gastric cancer on quality of life. Br J Surg. 2003;90:91-4.

31. Wagner AD, Unverzagt S, Grothe W, et al. Chemotherapy for advanced gastric cancer. Cochrane Database Syst Rev. 2010;3:CD004064. doi:10.1002/14651858.CD004064.pub3

32. Jack S, West MA, Raw D, et al. The effect of neoadjuvant chemotherapy on physical fitness and survival in patients undergoing oesophagogastric cancer surgery. Eur J Surg Oncol. 2014;40:1313-20.

33. Yu W, Park KB, Chung HY, et al. Chronological changes of quality of life in long-term survivors after gastrectomy for gastric cancer. Cancer Res Treat. 2016;48:1030-6. 